\title{
Cognitive function after two doses of cranial irradiation for acute lymphoblastic leukaemia
}

\author{
J Rodgers, P G Britton, J Kernahan, A W Craft
}

\begin{abstract}
The cognitive function of 23 children given cranial irradiation in a dose of $24 \mathrm{~Gy}$ was compared with that of 41 given $18 \mathrm{~Gy}$. No significant differences were found in intellectual function or in mean number of intelligence quotient points lost between patients in the two treatment groups. A reduction in the dose of cranial irradiation does not seem to alleviate long term neuropsychological deficits.
\end{abstract}

The philosophy of management of childhood malignancy has changed from one of cure at 'almost any cost' to one of 'cure at least cost'. This is exemplified by the treatment of acute lymphoblastic leukaemia in which increasing long term survival brought an awareness of neuropsychological deficits. The cranial irradiation given to treat occult disease of the central nervous system was regarded as the most likely cause of the observed cognitive problems. Because of this the dose of cranial irradiation given to most children in the United Kingdom was reduced in the mid 1980s from $24 \mathrm{~Gy}$ to 18 Gy. A previous study in Newcastle showed clear deficits in intellectual function in children with acute lymphoblastic leukaemia treated with 24 Gy when compared both with sibling controls and with children treated for solid tumours who had not received cranial irradiation.' ${ }^{\prime}$ A follow up of this initial cohort showed that the deficits persisted. ${ }^{2}$ The same methods have now been applied to a group of children with acute lymphoblastic leukaemia treated with $18 \mathrm{~Gy}$, and a comparison made with the original children treated with the higher dose of irradiation.

\section{Patients and methods}

Twenty three children (14 boys and nine girls) treated with $24 \mathrm{~Gy}$ and 41 (20 boys and 21 girls) treated with $18 \mathrm{~Gy}$ were studied, together with one sibling control for each. Their ages at

Royal Victoria Infirmary, Queen Victoria Road, Newcastle upon Tyne NE1 4LP. Psychiatry Research Unit J Rodgers

P G Britton

Department of

Child Health

J Kernahan

A W Craft

Correspondence to:

Miss Rodgers.

Accepted 23 May 1991

(Arch Dis Child 1991;66:1245-6) table 1.

Each child was given the four British Ability Scale subtests appropriate to their age. ${ }^{3}$ All

Table 1 Age of children at time of diagnosis and testing (months)

\begin{tabular}{llllll}
\hline $\begin{array}{l}\text { Irradiation } \\
\text { dose }\end{array}$ & \multicolumn{2}{l}{ Age at diagnosis } & \multicolumn{2}{l}{ Age at test } \\
\cline { 2 - 5 } \cline { 5 - 6 } & Mean $(S D)$ & Range & Mean (SD) & Range \\
\hline 24 Gy $(\mathrm{n}=23)$ & $48 \cdot 5(24 \cdot 1)$ & $16-105$ & $119(25 \cdot 8)$ & $88-182$ \\
18 Gy $(\mathrm{n}=41)$ & $56.0(36 \cdot 0)$ & $10-162$ & $118 \cdot 5(37 \cdot 0)$ & $55-253$ \\
\hline
\end{tabular}

Table 2 Mean (SD) IO before and after treatment and points lost in the two groups

\begin{tabular}{|c|c|c|}
\hline & Irradiation dose & \\
\hline & $\begin{array}{l}24 G y \\
(n=23)\end{array}$ & $\begin{array}{l}18 G y \\
(n=4 i)\end{array}$ \\
\hline $\begin{array}{l}\text { Estimate before treatment } \\
\text { After treatment } \\
\text { Points lost }\end{array}$ & $\begin{aligned} 104 \cdot 3 & (4 \cdot 4) \\
99 \cdot 1 & (13 \cdot 2) \\
5 \cdot 2 & (12 \cdot 4)\end{aligned}$ & $\begin{array}{r}105 \cdot 2(8 \cdot 8) \\
100 \cdot 9(15 \cdot 4) \\
4 \cdot 3(12 \cdot 5)\end{array}$ \\
\hline
\end{tabular}

received the similarities test (verbal reasoning), the matrices test (abstract reasoning), and the recall of digits test (immediate memory). Those over the age of $\mathbf{8}$ years were also given the speed of information processing test and those less than 8 were given the naming vocabulary test (retrieval and application of knowledge). A pretreatment estimate of intelligence quotient (IQ) was derived using a method described by McNemar, ${ }^{4}$ by which the patient is deemed to have an IQ halfway between the sibling's score and 100 -for example, the pretreatment estimate for a child whose sibling scores 130 is 115 , and if the sibling scored 90 the pretreatment estimate would be 95 .

\section{Results}

The results of the full scale IQ assessment are shown in table 2, together with estimates before treatment that were derived from the sibling scores. The mean (SD) loss of IQ in the $24 \mathrm{~Gy}$ group was $5 \cdot 2(12 \cdot 4)$ and in the 18 Gy group $4 \cdot 3$ $(12 \cdot 5)$. Student's $t$ test showed that there was no significant difference between the two groups in the number of IQ points lost.

The $t$ test also showed no significant difference in IQ scores between the two groups, and no significant differences in the shape of the profiles calculated for the individual subtests that comprised the IQ measurements in the two groups. A paired $t$ test, however, showed that patients in both groups had IQ ratings significantly below those of their calculated estimates before treatment $(24 \mathrm{~Gy}: \mathrm{p}<0 \cdot 05,18 \mathrm{~Gy}$ : $\mathrm{p}<0.01)$.

\section{Discussion}

These results indicate that children treated with $18 \mathrm{~Gy}$ have deficits that are almost identical to those identified earlier in the $24 \mathrm{~Gy}$ group. The reduction in the dose of radiation does not seem to have affected the degree of deficit. Two possible reasons for this could be that there has not been sufficient reduction in dose, or that the deficits are not caused by the irradiation. Several centres in the United States have been 
attempting to treat children without irradiation, but giving instead high doses of parenteral and intrathecal methotrexate to treat the occult disease of the central nervous system. Some recent studies have suggested that identical intellectual deficits may also be seen in these children suggesting either that the methotrexate causes similar problems to irradiation, or that intellectual damage might be caused by the disease itself.

There is no unanimity, however, in the reports of intellectual deficits in children with acute lymphoblastic leukaemia. Meadows et al were unable to show the same intellectual deficits in children treated with 18 Gy as they had described with $24 \mathrm{~Gy}^{5}$ Eiser has recently reviewed the whole problem of cognitive deficits in children treated for leukaemia. ${ }^{6}$ Clearly they do occur in many children and for some these are an educational and social handicap. Irrespective of the underlying cause of the problem, remedial help is warranted.

J Rodgers was supported by the Tyneside Leukaemia Research Association.

1 Twaddle V, Britton PG, Craft AW, Noble TG, Kernahan J. Intellectual function after treatment for leukaemia and solid tumours. Arch Dis Child 1983;58:949-52.

2 Twaddle V, Britton PG, Craft AW, Kernahan J. Intellect after malignancy. Arch Dis Child 1986;61:700-2.

3 Elliott G, Murray D, Pearson L. British ability scales. Windsor: NFER Publishing, 1978.

4 McNemar Q. Psychological statistics. Chichester: Wiley, 1962: 373.

5 Meadows AT. Cognitive function in children after $18 \mathrm{~Gy}$ cranial irradiation or periodic intrathecal methotraxate. Procranial irradiation or periodic intrathecal methotraxate. Pro71 .

6 Eiser C. Cognitive deficits in children treated for leukdemia. Arch Dis Child 1991;66:164-8.

\title{
Congenital neuroblastoma presenting with paraplegia
}

\author{
Fraser D Munro, Robert Carachi, Alasdair H B Fyfe
}

\begin{abstract}
Department of Paediatric Surgery, Royal Hospital for Sick Children,

Abstract

A girl presented with paraplegia at birth. A magnetic resonance scan showed an abdominal neuroblastoma with intraspinal extension. Treatment by chemotherapy did not produce any improvement in the neurological signs. Review of previously reported cases suggests the outlook for neurological recovery is poor regardless of treatment.
\end{abstract} Yorkhill, Glasgow G3 8S ] Fraser D Munro Robert Carachi Alasdair H B Fyfe Correspondence to: Mr Carachi.

Accepted 10 June 1991

(Arch DisChild 1991;66:1246-7)

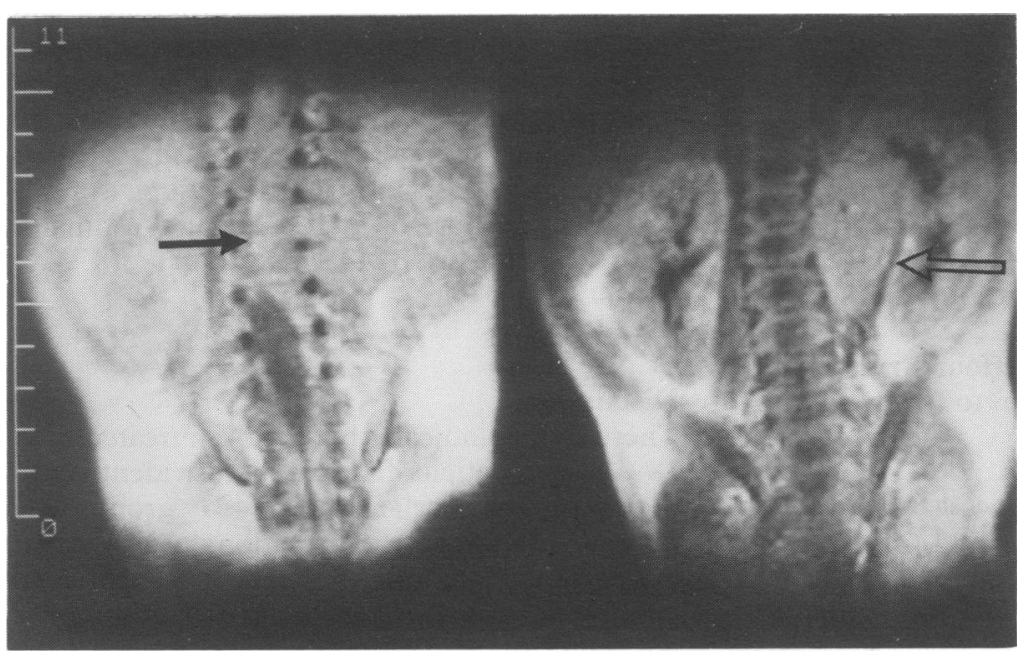

Magnetic resonance scan showing paraspinal tumour (open arrow) with intraspinal extension (black arrow).

\section{Case report}

A newborn girl, delivered at 38 weeks' gestation by mid cavity forceps, was noted to have bilateral drop foot, a patulous anus with bulging of the perineum, and bilateral subluxing hips. In the hours after birth she dribbled urine continuously. Plain spinal $x$ ray films showed expansion of the spinal canal between $\mathrm{T} 12$ and L2. A magnetic resonance scan showed an extradural tumour extending from $\mathrm{T} 12$ to $\mathrm{L} 3$, continuous through the intervertebral foramina with a paraspinal mass on the left side (figure). Her homovanillic acid concentration was $38 \cdot 8$ $\mu \mathrm{mol} / \mathrm{mmol}$ creatinine (normal $=<20$ ) and hydroxymethoxymandellic acid $30.4 \mu \mathrm{mol} /$ mmol creatinine (normal $=<9$ ) supporting a diagnosis of neuroblastoma. A biopsy specimen was taken from the abdominal portion of the tumour at laparotomy. Histology showed this to be a poorly differentiated neuroblastoma. At surgery the liver appeared normal and there were no identifiable lymph nodes. The baby was treated with chemotherapy (vincristine 1.5 $\mathrm{mg} / \mathrm{m}^{2}$, carboplatin $400 \mathrm{mg} / \mathrm{m}^{2}$, etoposide 150 $\mathrm{mg} / \mathrm{m}^{2}$, and cyclophoshamide $600 \mathrm{mg} / \mathrm{m}^{2}$ ).

This was well tolerated but there was no improvement in the neurological signs. Her unstable hips were managed in a Von-Rosen splint and her drop foot by ankle-foot orthoses.

\section{Discussion}

Congenital neuroblastoma presenting with paraplegia is rare. We have found another 15 cases reported in the literature (table). ${ }^{1-3}$ In all but one case the tumour appeared to be localised at diagnosis, the exception having hepatic metastases. The treatment given was variable. The majority underwent decompressive laminectomy with, in most cases, postoperative radiotherapy or chemotherapy. Two were treated by chemotherapy alone and none by radiotherapy alone, and one by vitamin B-12 alone. Survival appears good with only two deaths; however, the neurological outcome was very poor. 